\title{
Ventilator-associated pneumonia
}

\author{
CARLOS ROBERTO RIBEIRO DE CARVALHO
}

Over the last 50 years, the use of invasive ventilator support has undoubtedly represented an advance in the treatment of respiratory insufficiency. Although it saves many lives, the application of positive airway pressure via a prosthesis placed in the airways can produce many adverse effects. These adverse effects are well known: hemodynamic instability, especially in hypovolemic patients; higher frequency of respiratory infections due to the impairment of local defense mechanisms caused by the presence of the tube; and, most recently, injury caused by mechanical ventilation, which has been associated with the high alveolar pressures reached by some units as a consequence of an ill and highly heterogeneous lung.

These changes are associated with higher morbidity rates due to the systemic repercussions they provoke, generating an increase in hospital costs, as well as raising mortality rates in these patients.

In this context, ventilator-associated pneumonia (VAP) is one of the most feared adverse effects within the intensive care environment. In order to intervene therapeutically, we first need to recognize the extent of the problem. However, there have been few studies evaluating VAP epidemiology in Brazil.

In a cross-sectional (one-day prevalence) study carried out in 19 intensive care units (ICUs), with a combined total of 170 beds and 126 admitted patients, of a university hospital in São Paulo, the prevalence of $\mathrm{ICU}$-acquired infections was evaluated. Prior to the day of the study, $69 \%$ of the patients had been diagnosed with infection, and all of those patients were receiving antimicrobial treatment. Approximately 31\% of those patients had acquired their infection while in the ICU, whereas 33\% had acquired their infection while in the hospital but prior to being admitted to the ICU. Respiratory infections were the most frequent infections, accounting for $58.5 \%$ of all cases. ${ }^{(1)}$

In another study, carried out in 99 Brazilian hospitals, pneumonia was found to be responsible for $28.9 \%$ of all nosocomial infections, 50\% of which occurred in patients on mechanical ventilation. ${ }^{(2)}$ The results of these two studies give us an idea of the significance of this problem: it is quite common; it results in high morbidity; it greatly increases hospital costs; and it presents a high mortality rate.

One obstacle to performing this type of evaluation is the lack of a precise criterion for diagnosis. The definition of VAP is a pulmonary infection acquired 48 to $72 \mathrm{~h}$ after the patient has been submitted to endotracheal intubation and invasive mechanical ventilation. ${ }^{(3)}$ Suspicion of VAP arises when new or progressive pulmonary infiltrate appears on chest $\mathrm{X}$-rays, accompanied by clinical signs and by the following laboratory test results: fever $\left(>38^{\circ} \mathrm{C}\right)$; leukocytosis $(>10,000 / \mathrm{mm} 3)$ or leukopenia $(<4000 / \mathrm{mm} 3)$; and purulent tracheal secretions.(4) However, the accuracy of these criteria is low. As a result, more than one clinical criterion must be taken together with the X-ray criterion in order to increase the sensitivity and specificity. The use of clinical criteria alone can lead to misdiagnosis and inappropriate treatment. Note that these criteria are not very specific and can be present in many situations to which critically ill patients are exposed, such as atelectasis, cardiogenic pulmonary edema, pulmonary infarction, acute respiratory distress syndrome and alveolar hemorrhage.

In an attempt to increase the likelihood of diagnosing VAP, Pugin et al. created the Clinical Pulmonary Infection Score (CPIS) based on sputum smear microscopy and tracheal aspirate culture, as well as on the clinical findings at the time of diagnostic suspicion. ${ }^{(5)}$ The CPIS is an index with a maximum possible score of 12 points. A score of more than 6 
indicates a high probability of VAP. The CPIS presents 93\% sensitivity and 100\% specificity. These highly positive initial results have not been confirmed in subsequent studies, in which the accuracy was similar to that of the clinical criteria.

In a recent study carried out in six hospitals in Buenos Aires, Argentina, it was demonstrated that the serial and prospective use of a simplified version of the CPIS (with a maximum of 10 points) resulted in early diagnosis of VAP (prior to the appearance of the classical clinical signs of the disease). ${ }^{(6)} \ln$ that study, mortality rates were lower among the patients who received appropriate antibiotic treatment within $24 \mathrm{~h}$ after the results of the CPIS had raised clinical suspicion of VAP. Further studies should be carried out in order to validate this concept.

Risk factors for VAP can be classified as modifiable or nonmodifiable. Nonmodifiable risk factors include the following: age; severity (score) at admission to the ICU; and comorbidities (heart failure, chronic obstructive pulmonary disease, diabetes, neurological diseases, neoplasms, traumas and post-operative recovery).

Modifiable risk factors are related to the environment (microbiota) of the $\mathrm{ICU}$ itself. Therefore, it is essential to have knowledge of the micro-organisms that are most commonly found in the ICU. This favors rational and focused prescription of antimicrobials, since the empirical treatment should be administered promptly when there is suspicion of VAP.

In this issue of the Jornal Brasileiro de Pneumologia (Brazilian Journal of Pulmonology), Guimarães and Rocco present the results of an observational study carried out in the ICU of a university hospital in Rio de Janeiro. Their study was aimed at determining VAP prevalence in patients submitted to mechanical ventilation for more than $24 \mathrm{~h}$. It also aimed to identify the factors associated with VAP development and its inhospital prognosis. ${ }^{(7)}$ Over an 18-month period, 808 patients were admitted to the hospital. Of those, 278 were included in the study. Of the 278 patients, $38.1 \%$ developed VAP. The authors found that $45.3 \%$ of the cases of pneumonia were caused by Gram-negative bacteria, and that $43.4 \%$ were caused by multidrug-resistant bacteria. Guimarães and Rocco observed that VAP increased patient time on mechanical ventilation, as well as prolonging ICU and hospital stays. However, despite the high in-hospital mortality rate seen in the study sample as a whole $(45.3 \%$ in the $\mathrm{ICU}$ alone and $55.8 \%$ overall), there was no difference between patients with VAP and those without in terms of mortality. Logistic regression indicated that the factors associated with the development of VAP were acute sinusitis, atelectasis, immunodepression, acute respiratory distress syndrome and being on mechanical ventilation for more than 10 days. ${ }^{(7)}$

The data provided by this study make it possible for an ICU team of attending physicians to recognize the infectious agents that are most often found in their ICU. Therefore, the nosocomial infection control committees of every health care facility should periodically inform their respective ICU heads of the antimicrobial sensitivity profile of the micro-organisms that are most frequently found in their ICUs, since it is known that prompt treatment with appropriate antibiotics is associated with greater treatment success (lower mortality rates) in patients with VAP.

Another fundamental finding is the identification of factors associated with the development of VAP in the ICU. Based on the results of such studies, interventions can be devised in order to decrease the frequency of this type of nosocomial infection, which, in this study ${ }^{(7)}$ was 35.7 cases/1000 days on mechanical ventilation. This rate is much higher than those recently found in North-American hospitals. In the general (clinical/surgical) ICU of one university hospital in the USA, the mean frequency of VAP was found to be 4.6 cases/ 1000 days on mechanical ventilation and the 90th percentile was only of 9.9. ${ }^{(8)}$

It is my belief that further epidemiological studies of VAP should be carried out in other Brazilian hospitals in order to make our current situation more transparent and to facilitate the implementation of corrective measures, when justified.

CARLOS ROBERTO RIBEIRO DE CARVALHO

Tenured Associate Professor in Pneumology; Head of the Respiratory ICU of the Faculdade de Medicina da Universidade de São Paulo (FMUSP, University of São Paulo School of Medicine) Hospital das Clínicas, São Paulo, Brazil

\section{REFERENCES}

1. Toufen Junior C, Hovnanian AL, Franca SA, Carvalho CRR. Prevalence rates of infection in intensive care units of a tertiary teaching hospital. Rev Hosp Clin Fac 
Med Sao Paulo. 2003;58(5):254-9.

2. Prade SS, Oliveira ST, Rodrigues R, Nunes FA, Netto EM, Felix JQ, et al. Estudo brasileiro da magnitude das infecções hospitalares em hospitais terciários. Rev Contr Infec Hosp. 1995;2:11-24.

3. Pereira CA, Carvalho CRR, Silva JLP, Dalcolmo MMP, Messeder OHC. Parte 11 - Pneumonia Nosocomial.Consenso Brasileiro de Pneumonias em indivíduos adultos imunocompetentes. J Pneumol. 2001;27(Supl 1): S22-S40.

4. Johanson WG Jr, Pierce AK, Sanford JP, Thomas GD. Hospital-acquired respiratory infections with gramnegative bacilli. The significance of colonization of the respiratory tract. Ann Intern Med. 1972;77(5):701-6.

5. Pugin J, Auckenthaler R, Mili N, Janssens JP, Lew PD, Sutter PM. Diagnosis of ventilator-associated pneumonia by bacteriologic analysis of bronchoscopic and nonbronchoscopic "blind" bronchoalveolar lavage fluid. Am Rev Respir Dis. 1991;143(5 Pt 1):1121-9.

6. Luna CM, Aruj P, Niederman MS, Garzon J, Violi D, Prignoni A, et al. Appropriateness and delay to initiate therapy in ventilator-associated pneumonia. Eur Respir J. 2006;27(1):158-64.

7. Guimarães MMQ, Rocco JR. Prevalência e prognóstico dos pacientes com pneumonia associada á ventilação mecânica em um hospital universitário. J Bras Pneumol. 2006;32(4):339-46.

8. National Nosocomial Infections Surveillance (NNIS) System Report, data summary from January 1992 through June 2004, issued October 2004. Am J Infect Control. 2004;32(8):470-85. 